\title{
Surgical Outcome \& Cost Analysis of Single Stage Anterior Decompression and Cage Fixation in Patients with Thoracic and Lumbar Tuberculous Spondylitis: A Single Centre Experience Over Six - Years with Comprehensive Literature Review
}

\author{
FAIQA FILZA KHAN, MUHAMMAD MUKHTAR KHAN, ZAHOOR AHMED, TARIQ KHAN \\ Department of Neurosurgery, Northwest General Hospital \& Research Centre, Peshawar - Pakistan \\ DOI 10.36552/pjns.v24i2.450
}

\begin{abstract}
Objective: For Tuberculous spondylitis (TS) the optimal mode of management for extensive tuberculous spondylitis is still a subject of debate. We determined the outcome for single stage anterior decompression and cage fixation for dorso-lumbar TS.
\end{abstract}

Material and Methods: This prospective study was conducted between 2012 and 2018. Worsening or new onset neurological deficit, increasing deformity, large paraspinal abscess and those not responding to anti-tuberculous drug therapy were included. Patients with severe comorbidities (> ASA class III) and recurrent cases were excluded. Demographics, clinical features, radiological characteristics, intraoperative details, postoperative complications and follow-up condition were recorded.

Results: One patient with mean age of $45.6 \pm 14.9$ years with 17 (54.8\%) males and 14 (45.2\%) females. Mean symptoms duration was $71.9 \pm 29.4$ days. $41.9 \%$ had spasticity \& $25.8 \%$ had sphincter dysfunction on presentation. Half (48\%) of patients had a Frankel grade 3 or less bilaterally. Mean length of the procedure was $137.4 \pm 19.9$ minutes. $19.4 \%(n=6)$ had postoperative pulmonary complications, $16.1 \%(n=5)$ wound infection, $9.7 \%(n=3)$ had worsening of neurologic deficit and one $(3.2 \%)$ remained static. Graft extrusion and cage subsidence were noted in one (3.2\%) patient each. Favorable outcome was observed in $83.9 \%(n=26)$ while $16.1 \%(n=5)$ had unfavorable outcome. Mean out-of-pocket cost was 164677.4 \pm 11469.9 rupees (USD: 1187 approx).

Conclusion: Timely spinal decompression with stabilization at the onset of the Pott's disease in patients who fulfil the criteria as surgical candidates carries a promising outcome.

Keywords: Pott's disease, anterior decompression, cage fixation, single stage.

\section{INTRODUCTION}

Tuberculous spondylitis has remained a subject of clinical research for the last few decades. It is clear that majority of patients without neurological deficit or significant/progressive spinal deformity will respond well to anti-tubercular therapy, while surgical intervention is required for a subset of patients with neurological deficit, progressive deformity or extensive uncontrollable disease. ${ }^{1,2}$ In 1963, the Medical Research Council (MRC) Working Party on
Tuberculosis of the Spine conducted the famous Hong Kong study, which demonstrated the role of surgical intervention in patients with tuberculous spondylitis. ${ }^{3}$

This study demonstrated the effective role of conservative versus radical debridement. Radical debridement was popularised by Hodgson and Stock ${ }^{4}$ in 1956 and was famously known as the "Hong Kong operation". This consisted of thorough extirpation of tuberculous foci and dead slough with exposure of healthy edges which bleeds sparingly. ${ }^{5,6}$ This is 
followed by insertion of a strut graft. The Hong Kong operation is well known for its efficacy in radical removal of the infective focus, good rates of bony fusion and satisfactory deformity correction. ${ }^{7}$ The optimum surgical approach is, however, still under debate, as to whether the posterior or anterior approaches or their combination have superior efficacy in efficacy and safety. ${ }^{8,9}$

Since tuberculous focus in the thoracic and lumbar regions frequently involves the anterior two columns and paraspinal tissues, it is logical to that it will be more effective in removal of the diseased tissue and more directly decompress the spinal cord in the thoracic region. ${ }^{10,11}$ Single stage anterior approach is favoured because it avoids the need for turning over the patient after surgery, avoidance of another wound and hence lesser trauma and lower blood loss. Anterior decompression with strut grafting/cage fixation is the most logical and direct approach where both bony and paraspinal regions can be approached with good outcome in terms of infection control, deformity correction and bony fusion. ${ }^{12}$

In our region, tuberculous spondylitis is highly prevalent and patients are usually diagnosed very late in the disease course and with complications. In this background, we present our experience with the single stage anterior approach and cage fixation with additional emphasis on cost analysis.

\section{MATERIAL AND METHODS}

\section{Study Design}

This is a prospective observational study conducted between January 2012 and December 2017 (6 - years) at the Department of Neurological Surgery, Northwest General Hospital \& Research Centre, Peshawar, Pakistan.

\section{Inclusion Criteria}

We included adult cases (age 18 to 65 years) of tuberculous spondylitis (TS) with worsening or new onset neurological deficit, increasing spinal deformity, large paraspinal abscess and those not responding to anti-tuberculous drug therapy.

\section{Exclusion Criteria}

Patients with severe comorbidities (> ASA class III) and recurrent cases were excluded.

\section{Data Collection}

The institutional review board approved this study. An informed consent was obtained from all patients regarding treatment and inclusion in the study.

Clinical data was stored in a digital chart. Data was collected regarding patient demographics, time since diagnosis of tuberculous disease, duration of neurological or spinal functional deterioration, laboratory studies, radiological parameters (spinal levels, number of levels, presence of kyphotic deformity, paraspinal abscess), intraoperative details (length of the procedure, blood loss), and postoperative status (early or delayed complications, neurological recovery and final outcome at 6-months duration).

\section{Surgical Procedure}

The procedures were performed by a single consultant neurosurgeon with more than 10 - year experience in spinal surgeries (F. F. K) in collaboration with a consultant thoracic \& general surgeon. All procedures were performed under general anesthesia. Broad spectrum antibiotics (Ceftriaxone 1g) were administered intravenously. A lateral thoracic incision was used for thoracic exposure, while midline longitudinal incision was used for exposure through the abdomen. The thoracic/general surgeon performed the thoracoabdominal exposure, which was followed by spinal procedure (corpectomy/decompression with graft and cage placement), performed by the neurosurgeon. The spinal procedure involved paraspinal abscess drainage, curettage and debridement of all necrotic and infected bone until the bony edges were bleeding. Thoracic cages with an autologous graft from the patient's rib were used which was followed by fixation with plate and screws. Chest drains were placed and the wounds were closed in layers.

\section{Follow-up}

Postoperatively, the patients were placed in the intensive care unit for 24 to 48 hours. Postoperative prophylactic antibiotics (Ceftriaxone $1 \mathrm{~g} \mathrm{BD}$ ) for 72 hours. Postoperatively, anti-tuberculous drug therapy was started and continued for at least 12-months. A postoperative follow-up schedule was practiced and all patients were advised to come for a follow-up visit at two weeks postoperatively, then at 6 weeks, then 12 weeks, 24 weeks and 48 weeks. During follow-up, laboratory markers (ESR, CRP), and radiological 
investigations (plain radiography, CT spine) were used. Any wound related complications, neurologic functional status and resolution of active tuberculous focus were determined. The surgical tissue samples were sent for histopathological analysis.

\section{Outcome}

Favorable outcome was defined as complete neurological and functional recovery as well as resolution of tuberculous disease as indicated by radiology and laboratory markers.

Unfavorable outcome was defined as worsening or static neurological status, postoperative complications leading to repeat surgical procedure or delayed postoperative deterioration in the form of increasing spinal deformity, cage subsidence or extrusion or recurrence of the tuberculous infection at the same or other level as well as death.

\section{Data Analysis}

Data was analyzed using SPSS version 25.0. An independent samples t-test was performed for determining significance of mean difference for continuous variables with respect to the dichotomised outcome. Chi-square test was used to determine the association between categorical variables. Statistical significance was considered at $\mathrm{p} \leq 0.05$.

\section{RESULTS}

\section{Gender Distribution}

Of the 31 patients studied, there were $17(54.8 \%)$ males and $14(45.2 \%)$ females in a ratio of 1.2 to 1 .

\section{Age Incidence}

The mean age was $45.6 \pm 14.9$ years (range: 15 to 66 ).

\section{Clinical Features}

The mean duration since the diagnosis of tuberculosis to the diagnosis of spinal involvement was $71.9 \pm 29.4$ days (range: 30 to 150$)$. Backache $(\mathrm{n}=19,61.3 \%)$, night sweats $(\mathrm{n}=18,58.1 \%)$ and fever $(\mathrm{n}=17$, $54.8 \%$ ) were the most common presenting complaints. Other presenting features included spasticity $(\mathrm{n}=13$, $41.9 \%)$ and sphincter disturbance $(\mathrm{n}=8,25.8 \%)$. Almost half of the patients $(n=14,45.1 \%)$ had a power of $3 / 5$ or less in the lower limbs.

Radiologically, there were 24 (77.4\%) patients with dorsal column involvement while $22.6 \%(\mathrm{n}=7)$ had involvement of the lumbar or lumbosacral spine involvement. The majority $(\mathrm{n}=14,45.2 \%)$ patients had involvement of a single vertebral level while (29\%) had two levels and 8 (25.8\%) had involvement of 3 vertebral levels. Paraspinal abscess was present in $54.8 \%(\mathrm{n}=17)$ cases, while $7(22.6 \%)$ had a concomitant occurrence of thoracic empyema/effusion at the time of presentation. Twenty $(64.5 \%)$ of the samples had features of non-specific chronic inflammatory changes while the rest $(35.5 \%)$ had chronic granulomatous inflammation.

The mean procedure length was $137.4 \pm 19.9$ minutes (range: 105 to 180 ) with a mean blood loss of

Table 1: Clinical Variables Stratified for Outcome Groups.

\begin{tabular}{|c|c|c|}
\hline Study Variable & $\begin{array}{c}\text { Favorable } \\
\text { Outcome } \\
(n=26)\end{array}$ & $\begin{array}{c}\text { Unfavorable } \\
\text { Outcome } \\
(\mathbf{n}=5)\end{array}$ \\
\hline & $\mathbf{N}(\%)$ & $\mathbf{N}(\%)$ \\
\hline \multicolumn{3}{|l|}{ Gender } \\
\hline Male & $16(61.5 \%)$ & $1(20 \%)$ \\
\hline Female & $10(38.5 \%)$ & $4(80 \%)$ \\
\hline Comorbids & $13(50 \%)$ & $1(20 \%)$ \\
\hline \multicolumn{3}{|l|}{ Clinical Findings } \\
\hline Backache & $15(57.7 \%)$ & $4(80 \%)$ \\
\hline Spasticity & $11(42.3 \%)$ & $2(40 \%)$ \\
\hline Sphincter dysfunction & $6(23.1 \%)$ & $2(40 \%)$ \\
\hline Fever & $14(53.8 \%)$ & $3(60 \%)$ \\
\hline Night Sweats & $16(61.5 \%)$ & $2(40 \%)$ \\
\hline Radiculopathy & $13(50 \%)$ & $2(40 \%)$ \\
\hline Hyper-reflexia & $11(42.3 \%)$ & $2(40 \%)$ \\
\hline \multicolumn{3}{|l|}{ Complications } \\
\hline Hemo-pneumothorax & $4(15.4 \%)$ & - \\
\hline Chest infection & $5(19.2 \%)$ & $1(20 \%)$ \\
\hline Wound infection & $4(15.4 \%)$ & $1(20 \%)$ \\
\hline Neuro-worsening & $1(3.8 \%)$ & $2(40 \%)$ \\
\hline Static & - & $1(20 \%)$ \\
\hline Recurrence & - & - \\
\hline Cage subsidence & - & $1(20 \%)$ \\
\hline Graft extrusion & - & $1(20 \%)$ \\
\hline
\end{tabular}


$173.9 \pm 38.1 \mathrm{~mL}$ (range: 110 to $250 \mathrm{~mL}$ ). Postoperatively, 4 (12.9\%) patients had persistence (> 3 days) of hemo-pneumothorax, which resolved with vacuum assisted drainage of the thoracic cavity through a chest drain. Similarly, six (19.4\%) patients developed significant hospital acquired chest infection requiring a prolonged stay. Wound infection was observed in $5(16.1 \%)$ patients requiring prolonged (>2 weeks) antibiotic therapy. Staphylococcus aureus was the only organism cultured from infected wound patients. The mean hospital length of stay (LOS) was $8.2 \pm 2.2$ days (range: 5 to 14 ). Backache was relieved in all patients following the surgery.

We observed postoperative worsening of neurological function in $3(9.7 \%)$. Two of the patients progressed from $4 / 5$ power in the lower limbs to $1 / 5$. All of these patients recovered their function to $3 / 5$ at the end of $1^{\text {st }}$ month postoperatively, but never improved to complete neurological function. One patient remained static in terms of neurological recovery despite adequate decompression and

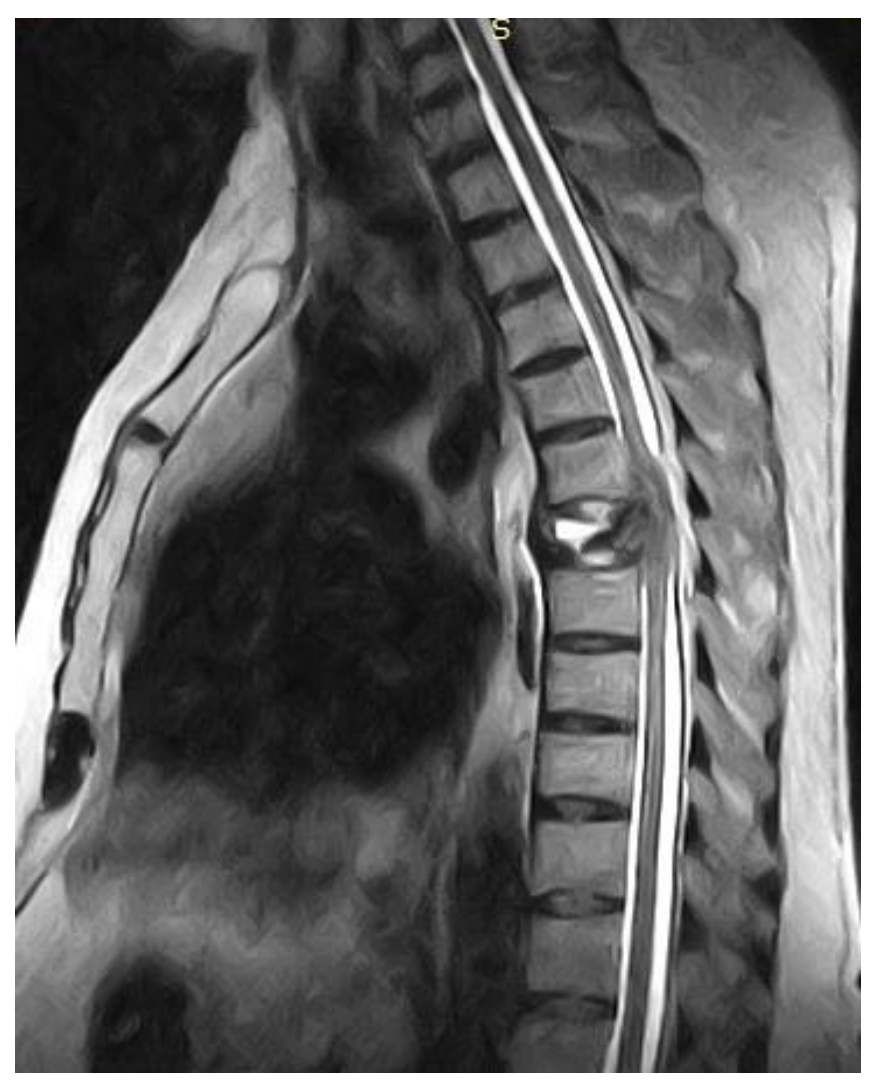

Fig. 1: Sagittal T2 MR Image of a 28 y male with involvement of D8 vertebra. The presenting signs were backache, lower limb weakness and sphincter dysfunction.
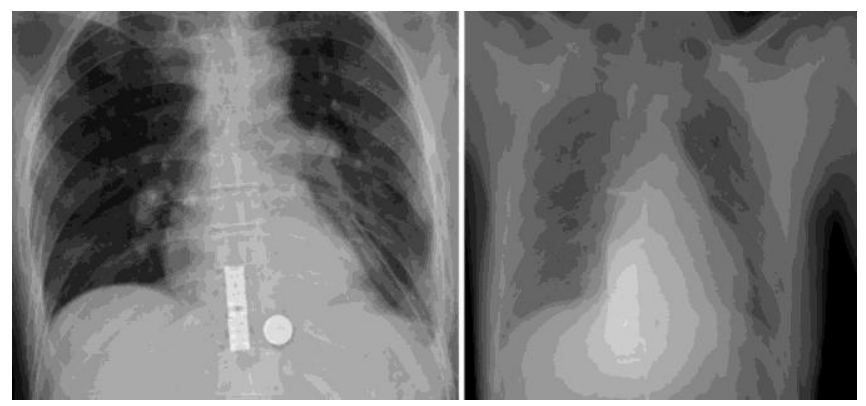

Fig. 2: Postoperative Radiographs of Some Patients Showing the Cages In-Situ.

remained bed bound during the 6 months of follow-up. There was one $(3.2 \%)$ cases each with cage subsidence and graft/cage extrusion. Both of these complications were noted at 3 months follow-up after mobilization, however, none of the cases required surgical correction as over the course of follow up both cases showed good fusion across the graft site. The cage subsidence patient was very mild (an estimate subsidence of $3 \mathrm{~mm}$ ) and was managed with bed rest for 6 weeks. Follow-up CT scan did not show progress, pain or neurological deterioration. We observed no disease recurrence during the follow-up period. The mean duration of follow-up was $9.5 \pm 2.6$ months (range: 6 to 16). At the end of the study, $83.9 \%(\mathrm{n}=26)$ patients were classified as having favorable outcome while $16.1 \%(\mathrm{n}=5)$ patients had unfavorable outcome.

The mean cost of in-hospital treatment, including surgery was $164677.4 \pm 11469.9$ PKR (Pakistani Rupee). On independent samples t-test, there was no significant difference between mean treatment costs for the two outcome groups. Similarly, on bivariate analysis, we did not observe statistically significant correlation between length of stay, procedure time or number of vertebral levels of the total cost.

On paired samples t-test, there was a significant mean difference (mean difference: $5.6 \pm 0.8, \mathrm{p}<$ 0.0001 ) for preoperative pain score (mean VAS: $7.2 \pm$ 2.3) as compared to postoperative pain score (mean postoperative VAS: $1.6 \pm 2.1)$. Similarly, there was a significant mean difference $\left(13.7^{\circ} \pm 0.9^{\circ}, \mathrm{p}<0.0001\right)$ between preoperative kyphotic angle $\left(22.4^{\circ} \pm 4.3^{\circ}\right)$ and postoperative kyphotic angle at final follow-up $\left(8.7^{\circ} \pm\right.$ $1.9^{\circ}$ ) for patients with lumbar region spondylitis. On the other hand, in patients with thoracic region spondylitis, the mean preoperative kyphotic angle was $44.2 \pm 4.3$ while it corrected significantly postoperatively and at final follow-up, the mean 
Surgical Outcome \& Cost Analysis of Single Stage Anterior Decompression and Cage Fixation in Patients

Table 2: Literature Review of Key Studies with Study Design, Sample Size and Conclusion.

\begin{tabular}{|c|c|c|c|}
\hline Author (Year) & Design/Sample & Approach studied & Conclusion \\
\hline Zhang et al $(2017)^{9}$ & Prospective (137) & $\begin{array}{l}\text { Anterior vs. Posterior } \\
\text { vs. Combined }\end{array}$ & $\begin{array}{l}\text { Posterior approach is superior to anterior and combined } \\
\text { approaches in terms of deformity correction, blood loss } \\
\text { and operative time. }\end{array}$ \\
\hline Wang et al $(2017)^{12}$ & Retrospective (69) & Anterior approach & $\begin{array}{l}\text { Anterior approach is safe and effective for } \\
\text { thoracolumbar TBS }\end{array}$ \\
\hline Yang et al $(2016)^{24}$ & Meta-analysis (2345) & $\begin{array}{l}\text { Anterior vs. Posterior } \\
\text { vs. Combined }\end{array}$ & $\begin{array}{l}\text { Posterior approach is superior to anterior and combined } \\
\text { approaches }\end{array}$ \\
\hline Cui et al $(2016)^{25}$ & Retrospective (81) & Anterior vs. posterior & $\begin{array}{l}\text { Posterior approach is superior to anterior } \\
\text { Higher incidence of sinus formation in posterior } \\
\text { approach }\end{array}$ \\
\hline Muheremu et al $(2015)^{8}$ & Meta-analysis (754) & Anterior vs. Posterior & $\begin{array}{l}\text { Posterior approach is superior for deformity correction, } \\
\text { otherwise no difference }\end{array}$ \\
\hline Liu et al $(2015)^{18}$ & Meta-analysis (253) & Posterior vs. Combined & $\begin{array}{l}\text { Posterior approach superior in terms of operation time, } \\
\text { blood loss and complications }\end{array}$ \\
\hline Wang et al (2014) ${ }^{12}$ & Prospective (115) & Combined vs. Posterior & $\begin{array}{l}\text { Posterior approach is superior in terms of lower } \\
\text { operative time, blood loss }\end{array}$ \\
\hline Shi et al $(2014)^{26}$ & Retrospective (148) & Anterior vs. Posterior & $\begin{array}{l}\text { Anterior and posterior approaches are similar in safety } \\
\text { and efficacy }\end{array}$ \\
\hline Li et al $(2011)^{7}$ & Retrospective (42) & Anterior & $\begin{array}{l}\text { Anterior approach is safe and effective for thoracic } \\
\text { TBS }\end{array}$ \\
\hline Cavuşoğlu et al (2008) ${ }^{22}$ & Prospective (22) & Anterior & $\begin{array}{l}\text { Anterior approach is safe and effective for multi-level } \\
\text { TBS }\end{array}$ \\
\hline Zhao et al $(2007)^{27}$ & Retrospective (40) & Anterior vs. Posterior & Both approaches are similar in efficacy and safety \\
\hline Dai et al $(2005)^{6}$ & Prospective (39) & Anterior & Anterior approach is safe and effective for TBS \\
\hline Klöckner et al $(2003)^{28}$ & Retrospective (71) & Anterior vs. Combined & $\begin{array}{l}\text { Anterior approach for single level disease } \\
\text { Combined for multi-level disease }\end{array}$ \\
\hline Ozdemir et al $(2003)^{5}$ & Retrospective (28) & Anterior & $\begin{array}{l}\text { Anterior approach is safe and effective for multi- } \\
\text { segment TBS }\end{array}$ \\
\hline
\end{tabular}

kyphotic angle was $32.1 \pm 4.3$ with a correction rate of $10.1 \%(\mathrm{p}<0.0001)$.

\section{DISCUSSION}

Spine is the most common region involved in skeletal tuberculosis and is reported to comprise $50 \%$ of cases of TB of the skeletal system. The social and economic consequences of tuberculous spondylitis are immense. ${ }^{10}$ In majority of cases, anti-tubercular drug therapy lead to successful resolution of the tuberculous lesions in the spine, however, $10 \%$ to $15 \%$ of the cases eventual surgical intervention either for deformity correction or spinal cord decompression. ${ }^{13,14,15}$
Literature is divided in recommending a single mode of surgical treatment and various studies have reported conflicting reports as to whether anterior, posterior or combined approaches are superior in managing tuberculous spondylitis (TBS). ${ }^{13}$

It is, however, evident that neurological deterioration, lack of response to medical management and progressive deformity eventually need surgical correction. Due to involvement of the anterior and middle column in TBS, the disease is most suitable to be approached from the anterior aspect, which gives wide exposure and decompression of the spinal cord without much manipulation. ${ }^{15}$ The debrided bony space can be supported with autografts using rib or 
fibula. The availability of titanium cages with graft space is also an attractive option, which gives the advantage of early stiffness and provides space for autograft that will help in fusion development. ${ }^{16}$

We conducted this study to determine the surgical outcome in terms of pain and functional improvement after decompression as well as the feasibility of this approach in both lumbar and dorsal spine. Presently there is a trend to use the posterior or posterolateral approaches for decompression and fixation. ${ }^{17}$ The anterior approach, though straight forward and the gold standard is slowly falling of favour for its limitations in deformity correction and being highly traumatic. ${ }^{18}$ In our community, good postoperative intensive care is very limited leading to a tendency among spinal surgeons for a preference towards posterior approaches. Another reason may be due to a lack of expertise in anterior spinal approaches. ${ }^{19}$

From our study, it is evident that the operative time was $137.4 \pm 19.9$ minutes. Similarly, the mean operative blood loss was a modest of $173.9 \pm 38.1 \mathrm{~mL}$. However, it is important to note that that the ease of an operative approach depends on personal expertise of a surgeon with a particular technique. ${ }^{20}$ Our study is also important in emphasizing the importance of the anterior approach since the postoperative outcome (in terms of pain resolution and neural recovery) was excellent while complication rates are low. Our study also shows that in both lumbar and thoracic spine involvement, the anterior approach is effective in relieving modest angular deformity. Most important benefit of the anterior approach is a good exposure of the tuberculous focus, especially in multiple levels involvement. Although, the posterior approach is regarded as effective in the correction of deformity and the strength of the posterior implants is superior to anterior instrumentation, this more direct route is effective in radically treating single and multi-level tuberculous spondylitis. ${ }^{16}$

From a recent review of studies, Fisahn et $\mathrm{al}^{21}$ have reviewed studies between year 2000 and 2016, to answer three important questions, i.e., i) indications for surgery, ii) favoured approaches and iii) reported outcome measures. They have shown that instability, neurological deficit, uncontrolled disease are the common indications for surgery while anterior and posterior approaches have been favoured equally across the studies. However, the posterior approach has been increasing in popularity between 2000 and 2016. Similarly, in pediatric patients, a combined approach is recommended.
Several studies have shown the efficacy of either the posterior or posterolateral approaches while others $^{20,22,23}$ have emphasized the importance of the anterior approach. Our literature review shows that the choice of procedure is dependent upon various indicators, such as age and comorbidities, number of levels involved, extent of deformity, the presence of paraspinal/psoas abscess and surgeon's preference.

The mean cost of the procedure in our study was $164677.4 \pm 11469.9$ PKR (USD: 1187). Although, the cost is low in terms of international surgical costs, for a country whose per capita GDP is only 1482 USD, it is very high and people are usually thrown into catastrophic poverty once they are diagnosed or undergone treatment for their disease. It is important to mention that this cost was only estimated from the hospital charges, and actual out of pocket costs may differ, and various factors such as transportation, food, diagnostic workup and indirect cost incurred by inability to perform duties are significantly higher. For the cost of the procedure, we could not compare it to the cost of the posterior approach as we did not have a comparative group.

\section{Limitation of the Study}

The limitations of our study include smaller sample size, no comparative group of posterior approach and single centre experience. A comparative design with posterior approach patients will be more suitable to establish the role of each type of approach for a particular situation.

\section{CONSLUSION}

Anterior radical debridement in tuberculous spondylitis is a safe and effective approach with lower rates of complications, effective debridement, good deformity correction and control of the tuberculous focus in Thoracic and Lumbar Carris Spine.

\section{REFERENCES}

1. Jain AK. Tuberculosis of the spine: a fresh look at an old disease. J Bone Joint Surg Br. 2010; 92 (7): 905-13.

2. Gautam MP, Karki P, Rijal S, Singh R. Pott's spine and paraplegia. JNMA J Nepal Med Assoc. 2005; 44 (159): 106-15.

3. A 15-year assessment of controlled trials of the management of tuberculosis of the spine in Korea and Hong Kong. Thirteenth Report of the Medical Research Council Working Party on Tuberculosis of the Spine. J Bone Joint Surg Br. 1998; 80 (3): 456-62. 
4. Hodgson AR, Stock FE. Anterior spinal fusion a preliminary communication on the radical treatment of Pott's disease and Pott's paraplegia. Br J Surg. 1956; 44 (185): 266-75.

5. Ozdemir HM, Us AK, Ogun T. The role of anterior spinal instrumentation and allograft fibula for the treatment of pott disease. Spine (Phila Pa 1976). 2003; 28 (5): 474-9.

6. Dai LY, Jiang LS, Wang W, Cui YM. () Single-stage anterior autogenous bone grafting and instrumentation in the surgical management of spinal tuberculosis. Spine (Phila Pa 1976); 2005; 30 (20): 2342-9.

7. Li M, Du J, Meng H, Wang Z, Luo Z. One-stage surgical management for thoracic tuberculosis by anterior debridement, decompression and autogenous rib grafts, and instrumentation. Spine. 2011; J 11 (8): 726-33.

8. Muheremu A, Niu X, Wu Z, Tian W. () Study on anterior and posterior approaches for spinal tuberculosis: a meta-analysis. Eur J Orthop Surg Traumatol 25 Suppl. 2015; 1: S69-76.

9. Zhang H, Guo Q, Guo C, et al. A medium-term followup of adult lumbar tuberculosis treating with 3 surgical approaches. Medicine, 2017; 96 (45): e8574.

10. Rasouli MR, Mirkoohi M, Vaccaro AR, Yarandi KK, Rahimi-Movaghar V. Spinal tuberculosis: diagnosis and management. Asian Spine J. 2012; 6 (4): 294-308.

11. Khoo LT, Mikawa K, Fessler RG. () A surgical revisitation of Pott distemper of the spine. Spine J. 2003; 3 (2): 130-45.

12. Wang WJ, Chen WK, Yan YG, Yao NZ, Wang C. Application of anterior debridement and reconstruction with anatomical screw-plate fixation for lumbosacral tuberculosis: A 2-year-plus follow-up. Medicine, 2017; 96 (26): e7103.

13. Tuli SM. Historical aspects of Pott's disease (spinal tuberculosis) management. Eur Spine J 22 Suppl. 2013; 4: 529-38.

14. Tuli SM. Tuberculosis of the spine: a historical review. Clin Orthop Relat Res. 2007; 460: 29-38.

15. Pola E, Rossi B, Nasto LA, Colangelo D, Logroscino CA. Surgical treatment of tuberculous spondylodiscitis. Eur Rev Med Pharmacol Sci 2012; 16 Suppl. 2: 79-85.

16. Patankar AP. Tuberculosis of spine: An experience of 30 cases over two years. Asian J Neurosurg. 2016; 11 (3): 226-31.

17. Meena S, Mittal S, Chowdhary B. Spinal tuberculosis: Which is the best surgical approach? Medical Principles and Practice, 2014; 23 (1): 96-7.
18. Liu J, Wan L, Long X, Huang S, Dai M, Liu Z. Efficacy and safety of posterior versus combined posterior and anterior approach for the treatment of spinal tuberculosis: A meta-analysis. World Neurosurg. 2015; 83 (6): 1157-65.

19. Jin W, Wang Q, Wang Z, Geng G. Complete debridement for treatment of thoracolumbar spinal tuberculosis: a clinical curative effect observation. Spine J. 2014; 14 (6): 964-70.

20. Cheng Z, Wang J, Zheng Q, Wu Y, Guo X. Anterolateral radical debridement and interbody bone grafting combined with transpedicle fixation in the treatment of thoracolumbar spinal tuberculosis. Medicine, 2015; 94 (14): e721.

21. Fisahn C, Alonso F, Hasan GA, et al. Trends in spinal Ssrgery for Pott's Disease (2000-2016): An Overview and Bbbliometric study. Global Spine J. 2017; 7(8): 821-8.

22. Cavusoglu H, Kaya RA, Turkmenoglu ON, Tuncer C, Colak I, Aydin Y. A long-term follow-up study of anterior tibial allografting and instrumentation in the management of thoracolumbar tuberculous spondylitis. J Neurosurg Spine, 2008; 8 (1): 30-8.

23. Cheung WY, Luk KD. Clinical and radiological outcomes after conservative treatment of TB spondylitis: is the 15 years' follow-up in the MRC study long enough? Eur Spine J. 2013; 22 Suppl. 4: 594-602.

24. Yang P, Zang Q, Kang J, Li H, He X. Comparison of clinical efficacy and safety among three surgical approaches for the treatment of spinal tuberculosis: a meta-analysis. Eur Spine J. 2016; 25 (12): 3862-74.

25. Cui X, Li LT, Ma YZ. Anterior and Posterior Instrumentation with Different Debridement and Grafting Procedures for Multi-Level Contiguous Thoracic Spinal Tuberculosis. Orthop Surg. 2016; 8 (4): 454-61.

26. Shi J, Tang X, Xu Y, et al. Single-stage internal fixation for thoracolumbar spinal tuberculosis using 4 different surgical approaches. J Spinal Disord Tech. 2014; 27 (7): E247-57.

27. Zhao J, Lian XF, Hou TS, Ma H, Chen ZM. Anterior debridement and bone grafting of spinal tuberculosis with one-stage instrumentation anteriorly or posteriorly. International orthopaedics, 2007; 31 (6): 859-63.

28. Klockner C, Valencia R. Sagittal alignment after anterior debridement and fusion with or without additional posterior instrumentation in the treatment of pyogenic and tuberculous spondylodiscitis. Spine (Phila Pa 1976). 2003; 28 (10): 1036-42. 


\section{Additional Information}

Disclosures: Authors report no conflict of interest.

Ethical Review Board Approval: The study was conformed to the ethical review board requirements.

Human Subjects: Consent was obtained by all patients/participants in this study.

Conflicts of Interest:

In compliance with the ICMJE uniform disclosure form, all authors declare the following:

Financial Relationships: All authors have declared that they have no financial relationships at present or within the previous three years with any organizations that might have an interest in the submitted work.

Other Relationships: All authors have declared that there are no other relationships or activities that could appear to have influenced the submitted work.

Address for Correspondence:

Faiqa Filza Khan

Department of Neurosurgery, Northwest General Hospital \& Research Centre, Peshawar-Pakistan

Email: faiqafilza@nwgh.pk

AUTHORSHIP AND CONTRIBUTION DECLARATION

\begin{tabular}{|l|l|l|}
\hline Sr.\# & Author's Full Name & Intellectual/Contribution to Paper in Terms of: \\
\hline 1. & Faiqa Filza Khan & 1. Main investigator/ data collection. \\
\hline 2. & Muhammad Mukhtar Khan & 2. Data analysis and report writing \\
\hline 3. & Zahoor Ahmed & 3. Literature review and Manuscript writing \\
\hline 4. & Tariq Khan & 4. Analysis of data and quality insurance \\
\hline
\end{tabular}

Date of Submission: 19-4-2020

Date of Revision: 31-05-2020

Date of Online Publishing: 30-06-2020

Date of Print: 30-07-2020 